\title{
SISTEM INFORMASI PENYEWAAN ALAT OUTDOOR DI RINJANI ADVENTURE
}

\author{
Pradina Muharditya $^{1}$, Harry Dhika ${ }^{2}$, Noor Komari Pratiwi ${ }^{3}$ \\ Program Studi Informatika, Fakultas Teknik dan Ilmu Komputer, Universitas Indraprasta PGRI \\ Jl. Raya Tengah No. 80, Kel. Gedong, Kec. Pasar Rebo, Jakarta Timur 13760 \\ pmditya@gmail.com¹, dhikatr@yahoo.com², noorkomaripratiwi01@gmail.com ${ }^{3}$
}

\begin{abstract}
Abstrak
Permasalahan dari sistem pendataan penyewaan alat outdoor di Rinjani Adventure yaitu lambatnya pencarian pendataan pelanggan, serta proses penyewaan dan pengembalian alat outdoor yang diakibatkan karena sistem yang diterapkan masih bersifat manual dan belum terkomputerisasi. Dari persoalan tersebut, peneliti tertarik untuk mengembangkan sistem informasi penyewaan alat outdoor di Rinjani Adventure yang ada saat ini sehingga dapat mengatasi kekurangan yang ada. Seiring dengan semakin maju teknologi yang berkembang, komputer telah mendorong terjadinya perubahan ilmu, baik dalam kajian ataupun implementasi dilapangan. Peran teknologi komputer sangat diperlukan oleh berbagai perusahaan. Mengingat kebutuhan akan peningkatan efisiensi dan efektifitas dari setiap kegiatan dalam instansi tidak dapat diukur dan dilakukan secara cepat dan akurat tanpa adanya dukungan teknologi tersebut. Tujuan dibuatnya sistem informasi ini untuk memudahkan proses penyewaan alat outdoor serta mempercepat pencarian data pelanggan, proses penyewaan dan pengembalian alat outdoor. Akurasi data, kecepatan waktu dan relevansi menjadi penentu kualitas informasi yang dihasilkan. Dengan menggunakan metode pengembangan sistem yaitu Waterfall dalam penelitian ini adalah dengan tahapantahapan seperti rekayasa sistem, analisis, desain, coding, testing, dan maintenance. Hasil dari penelitian ini adalah menciptakan aplikasi untuk penyewaan alat outdoor yang efektif dan efisien.
\end{abstract}

Kata Kunci : Sistem, Penyewaan, Alat Outdoor

\begin{abstract}
The problem of the outdoor Tool Rental collection system in Rinjani Adventure is the slow search of customer data, as well as the process of rental and refunding of outdoor tools that result from the system that is applied is still manual and not computerized. From the issue, researchers are interested in developing an outdoor equipment rental Information system in Rinjani Adventure that exists today so as to overcome the shortcomings. As the technology progressed, the computer has encouraged the changing of the science, either in the study or implementation of the field. The role of computer technology is indispensable to various companies. Given the need for increased efficiency and effectiveness of each activity in the institution cannot be measured and carried out quickly and accurately without the support of such technology. The purpose of This information system is to facilitate the outdoor equipment rental process as well as accelerate the search for customer data, the rental process and the return of outdoor equipment. Data accuracy, time speed and relevance become the quality determinant of the resulting information. By using a system development method that is waterfall in the research is with stages such as system engineering, analysis, design, coding, testing, and maintenance. The result of this research is creating an application for an effective and efficient outdoor tool rental.
\end{abstract}

Keywords : System, Lease, Outdoor Tools

\section{PENDAHULUAN}

Berkembangnya usaha-usaha perdagangan yang sangat pesat saat ini menjadikan informasi sebagai hal yang sangat penting peranannya dalam menunjang jalannya operasi-operasi demi tercapainya tujuan yang diinginkan oleh perusahaan. Perusahaan membutuhkan suatu sistem yang dapat meningkatkan kinerja agar menjadi lebih efisien. Sistem informasi memiliki peranan sebagai media pengolah data. Sistem informasi yaitu kombinasi antara prosedur kerja, informasi, orang, dan teknologi informasi yang diorganisasikan untuk mencapai tujuan dalam sebuah organisasi. Sistem adalah merupakan suatu bentuk integrasi antara satu komponen dengan komponen lain karena sistem memiliki sasaran yang berbeda untuk setiap kasus yang terjadi dalam sistem tersebut (Sutabri, 2012). Penyewaan adalah suatu 
perjanjian dengan mana pihak yang satu mengikatkan dirinya untuk memberikan kepada pihak yang lainnya kenikmatan dari suatu barang, selama suatu waktu tertentu dan dengan pembayaran suatu harga yang oleh pihak yang tersebut terakhir itu disanggupi pembayarannya (Subekti, 2014).

Rinjani Adventure adalah sebuah perusahaan yang bergerak dibidang jasa penyewaan alat outdoor. Meskipun perusahaan ini sudah berdiri cukup lama akan tetapi masih ada kendala di pendataan penyewaan alat outdoor sehingga bisnisnya pada semua bagian dilakukan manual atau belum terkomputerisasi. Hal tersebut menyebabkan sulitnya customer dalam mencari informasi penyewaan dikarenakan promosi yang dilakukan oleh Rinjani Adventure hanya melalui penyebaran brosur dijalan dan proses penyewaan yang menuntut customer untuk datang langsung ke Rinjani Adventure. Masalah tersebut merupakan masalah klasik yang dimiliki oleh setiap perusahaan yang kurang terbuka oleh kemajuan teknologi sehingga masyarakat akan memilih alternative lain seperti mencari perusahaan lain yang bergerak dibidang yang sama dan dapat diakses dengan mudah melalui internet. Oleh karena itu dibutuhkan sistem terkomputerisasi yang dapat memudahkan dalam proses penyewaan alat outdoor serta mempercepat pencarian data pelanggan serta proses penyewaan dan pengembalian alat outdoor

\section{PENELITIAN RELEVAN}

Dalam penelitian yang berjudul Sistem Informasi Penyewaan Peralatan Pesta Pada Saung Kuring di Cidaun Berbasis Web dengan peneliti yang bernama Rino Ade Lesmana Wijaya memiliki hasil penelitian membangun sistem informasi peralatan pesta pada Saung Kuring dapat memudahkan seorang konsumen untuk melihat informasi yang berkaitan dengan alat pesta pada Saung Kuring. Diharapkan tidak adanya kesalahan pengecekan stok perlengkapan yang tercatat di data dengan perlengkapan dengan yang tersedia di gudang. Sudah tidak adanya kesalahan pencatatan transaksi pembayaran dan laporan karena kehilangan/kerusakan berkas.

Dalam penelitian yang berjudul Perancangan Sistem Pengadaan Barang pada PT. Adiyasa Persada Jakarta Selatan dengan peneliti yang bernama Baimais Wasahua, memiliki hasil penelitian merancang suatu sistem pengadaan yang mampu mengolah data barang yang bermanfaat bagi perusahaan serta menganalisa keutuhan perusahaan tentang seluruh informasi pengadaan barang pada PT. Adiyasa Persada Jakarta Selatan.

\section{METODE PENELITIAN}

Metodologi pengembangan sistem yang digunakan Waterfall (Jogiyanto, 2010), dengan tahapan seperti gambar sebagai berikut:

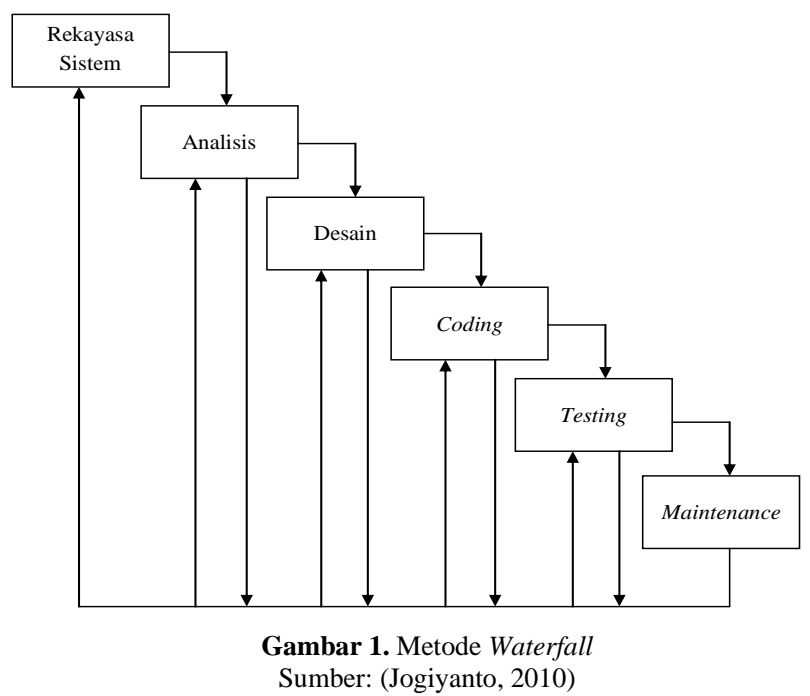


Berikut ini adalah penjelasan dari tahapan-tahapan yang terdapat dalam metode Waterfall:

1. Rekayasa Sistem, merupakan tahap awal dari pembangunan perangkat lunak, yaitu menetapkan segala hal yang diperlukan dalam pelaksanaan pembangunan perangkat lunak dan menentukan apakah sistem benar-benar dibutuhkan.

2. Analisis, merupakan tahap dimana rekayasa perangkat lunak menganalisa hal-hal yang diperlukan dalam pembuatan suatu aplikasi yang akan dibuat.

3. Desain, merupakan tahap penterjemahan dari keperluan data-data yang telah dianalisa kedalam bentuk yang mudah dimengerti oleh pemakai.

4. Coding, adalah tahap penterjemahan data pemecah masalah yang telah dirancang kedalam bahasa pemograman komputer yang telah ditentukan.

5. Testing, merupakan tahap pengujian terhadap perangkat lunak yang telah selesai dibuat untuk menemukan kesalahan-kesalahan atau kekurangan yang terdapat di dalam sistem. Pada pengujian ini peneliti menggunakan pengujian black box. Pengujian black box adalah pengujian aspek fundamental system tanpa memperhatikan struktur logika internal perangkat lunak. Metode ini digunakan untuk mengetahui apakah perangkat lunak berfungsi dengan benar. Pengujian black box merupakan metode perancangan data uji yang didasarkan pada spesifikasi perangkat lunak. Data uji dieksekusi pada perangkat lunak dan kemudian keluar dari perangkat lunak dicek apakah telah sesuai dengan yang diharapkan.

Pengujian black box berusaha menemukan kesalahan dalam kategori:

a. Fungsi-fungsi yang tidak benar atau hilang.

b. Kesalahan interface, kesalahan dalam tampilan layar.

c. Kesalahan pada struktur data atau akses database.

d. Kesalahan performansi, kesalahan inisialisasi dan tujuan akhir.

6. Maintenance, yaitu tahap akhir dimana perangkat lunak yang sudah selesai dan mengalami perubahan atau penambahan sesuai dengan permintaan. Bagian ini merupakan bagian terujung dari siklus pengembangan sistem laporan data administrasi. Pada tahapan ini dilakukan kegiatan corrective maintenance, yaitu mengkoreksi kesalahan pada perangka lunak yang baru diketahui pada saat perangkat lunak dipergunakan. Dengan adanya corrective maintenance terhadap sistem laporan data penyewaan, maka kesalahan-kesalahan yang terdapat pada sistem penyewaan ini dapat diperbaiki.

\section{HASIL DAN PEMBAHASAN}

\section{Analisa Permasalahan}

Pada sistem informasi penyewaan alat outdoor di Rinjani Adventure ini ternyata mempunyai beberapa permasalahan karena sistem yang digunakan belum sepenuhnya terkomputerisasi.

1. Penulisan data penyewaan alat outdoor masih dilakukan secara manual.

2. Proses pencatatan secara manual memerlukan tempat penyimpanan yang sangat luas, akibat kertas yang bertumpuk serta memerlukan waktu yang lama dalam proses pencarian data kembali.

3. Pelayanan terhadap pelanggan menjadi tidak efisien dan mungkin akan terjadi kesalahan akibat waktu yang lama dalam pencarian data.

4. Pembuatan laporan yang dilakukan secara manual memungkinkan terjadinya kesalahan yang memerlukan waktu yang lama dalam mengubahnya.

\section{Alternatif Penyelesaian Masalah}

Untuk mencari solusi dalam permasalahan yang ada maka peneliti membuat suatu sitem yang akan membantu dalam menyelesaikan masalah tersebut. Berdasarkan analisa sistem yang sedang berjalan saat ini peneliti melihat beberapa kelemahan dan pokok permasalahan yang terdapat pada sistem penyewaan alat outdoor di Rinjani Adventure di atas, maka peneliti memberikan saran beberapa alternatif penyelesaian masalah diantaranya: 
1. Agar tidak terjadi keterlambatan didalam proses pengerjaan dan informasi, sebaiknya dikoordinasikan dengan baik dan terkomputerisasi dengan benar antara sub sistem yang satu dengan yang lainnya, outlet Rinjani Adventure sebaiknya membuat rancangan sistem yang dapat meringankan dalam mengerjakan, mengumpulkan dan mengecek data-data khususnya pada pengolahan data penyewaan alat outdoor dan pembuatan laporan.

2. File ataupun data yang sudah dikerjakan sebaiknya disimpan ke Hardisk atau alat penyimpanan data lain, dan jika perlu dibuat backup-nya jika saat terjadi kesalahan kita masih memiliki cadangan file ataupun data-datanya.

3. Alangkah baiknya bila komputer yang digunakan untuk memproses data di upgrade, sehingga pemrosesan data tersebut dapat dilakukan lebih baik, cepat (menghemat waktu) dan tepat. Dengan dibuatnya sistem alat outdoor di Rinjani Adventure dengan sistem terkomputerisasi ini, diharapkan harapkan dapat mempermudah proses pengerjaan dan pengecekan data khususnya pada proses pembuatan laporan dan pengolahan data penyewaan alat outdoor.

\section{Diagram Kontek}

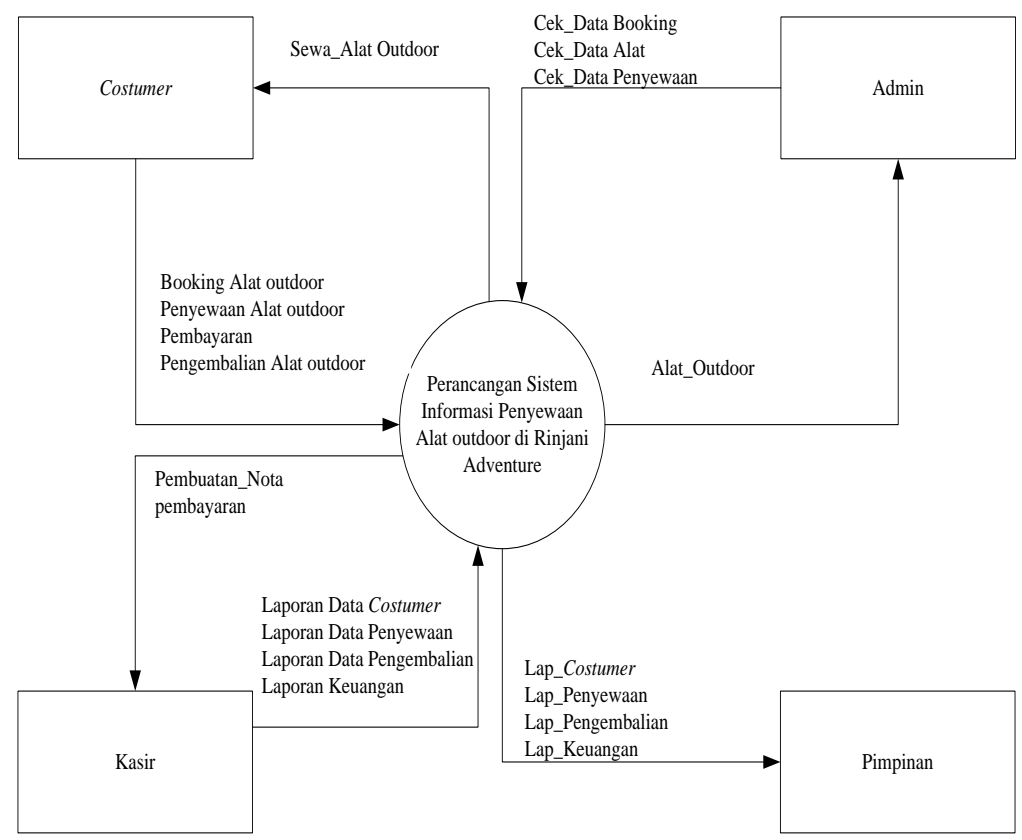

Gambar 2. Diagram Konteks

Pada diagram diatas memperlihatkan gambaran umum dari sistem informasi penyewaan alat outdoor, karena sebuah subsistem hanya diwakili oleh satu simbol proses. Subsistem penyewaat alat outdoor ini berinteraksi dengan kesatuan luar atau kelompok pengguna yaitu Admin, Pimpinan, Customer dan Kasir. Admin dapat login dan mengakses semua data pada semua komponen. Customer dapat menyewa dan membooking alat outdoor. Kasir pembuatan pembayaran dan pembuatan nota. Untuk pimpinan hanya menerima dan melihat seluruh laporan yang ada pada sistem penyewaan alat outdoor.

\section{Entity Relationship Diagram (ERD)}

Entity Relationship Diagram (ERD) adalah Entity Relationship Diagram (ERD) dikembangkan berdasarkan teori himpunan dalam bidang matematika. ERD digunakan untuk pemodelan basis data relasional (Shalahuddin, 2013). 


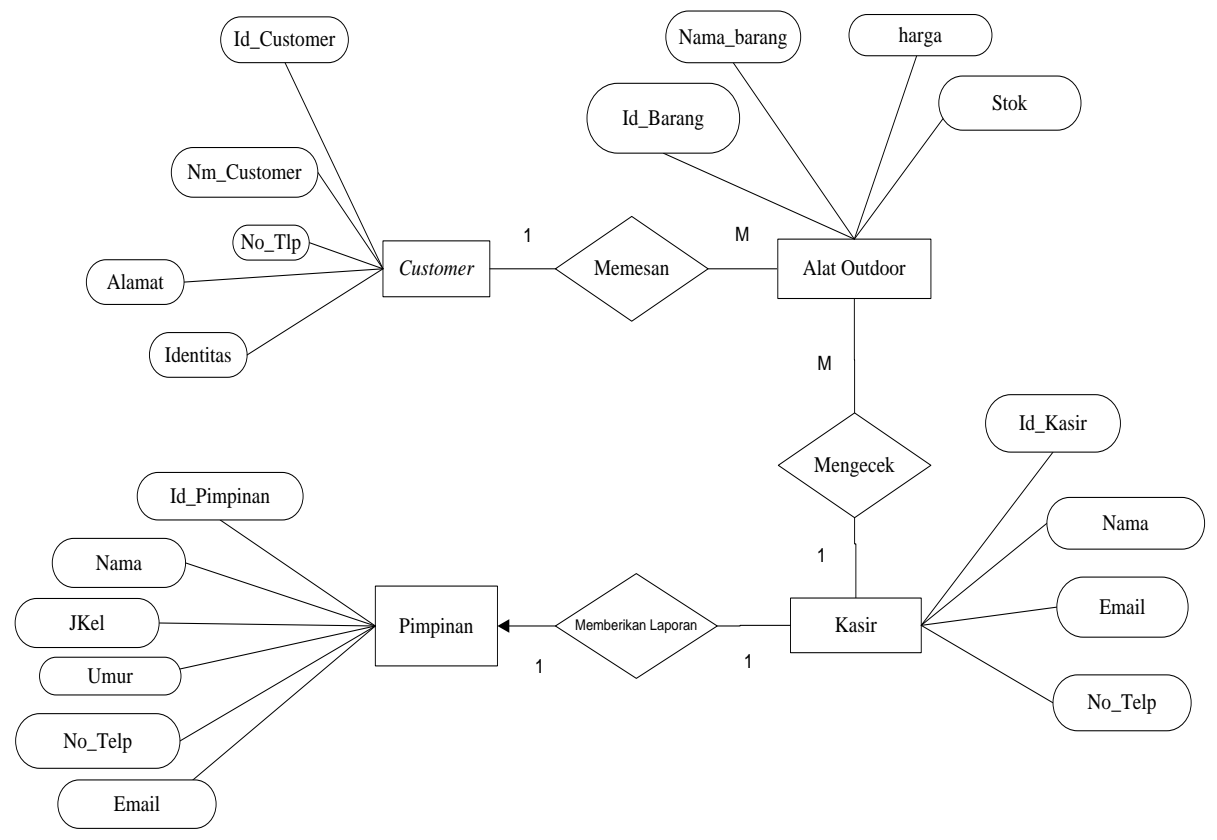

Gambar 3. Entity Relationship Diagram

Pada gambar diatas dapat dijelaskan bahwa admin dapat mengakses semua entitas atau komponen. Admin dapat melakukan pendataan identitas customer. Customer dapat melakukan penyewaan alat outdoor dan serta kasir dapat membuat nota pembayaran untuk customer. Dan pimpinan nantinya akan dibuatkan laporan hasil dari penyewaan alat outdoor tersebut.

\section{Tampilan Layar Sistem}

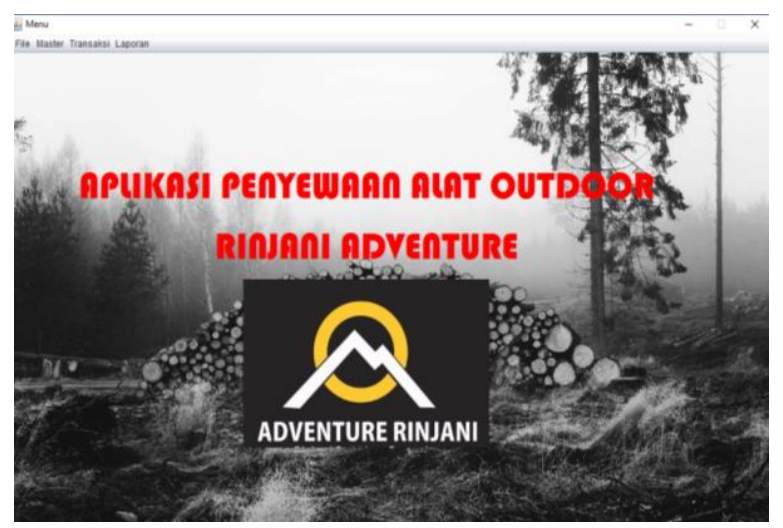

Gambar 4. Tampilan Layar Menu Utama

Layar di atas menampilkan tampilan Menu Utama pada Sistem Penyewaan Alat Outdoor di Rinjani Adventure Pada layar utama tersedia menu bar yang terdiri dari master data yang digunakan untuk memasukkan data yang berkaitan dengan Data Barang, Data Pelanggan, Data Penyewaan, Data Pengembalian dan Laporan-laporan. 


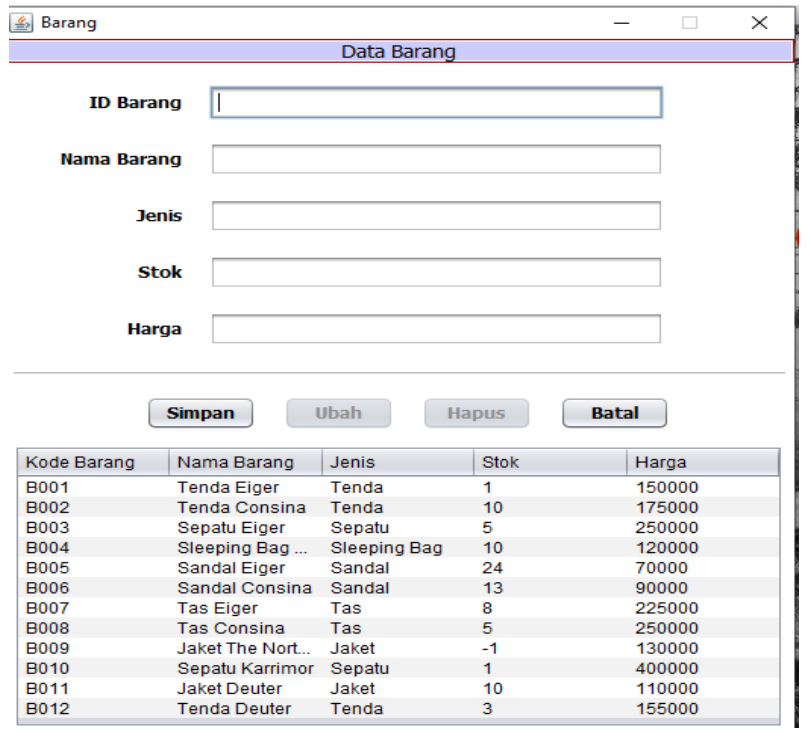

Gambar 5. Tampilan Layar Data Barang

Layar di atas menampilkan tampilan form data barang. Pada layar form data barang untuk meng-input data barang yang terdiri dari Kode barang, nama barang, kode jenis, harga dan stok.

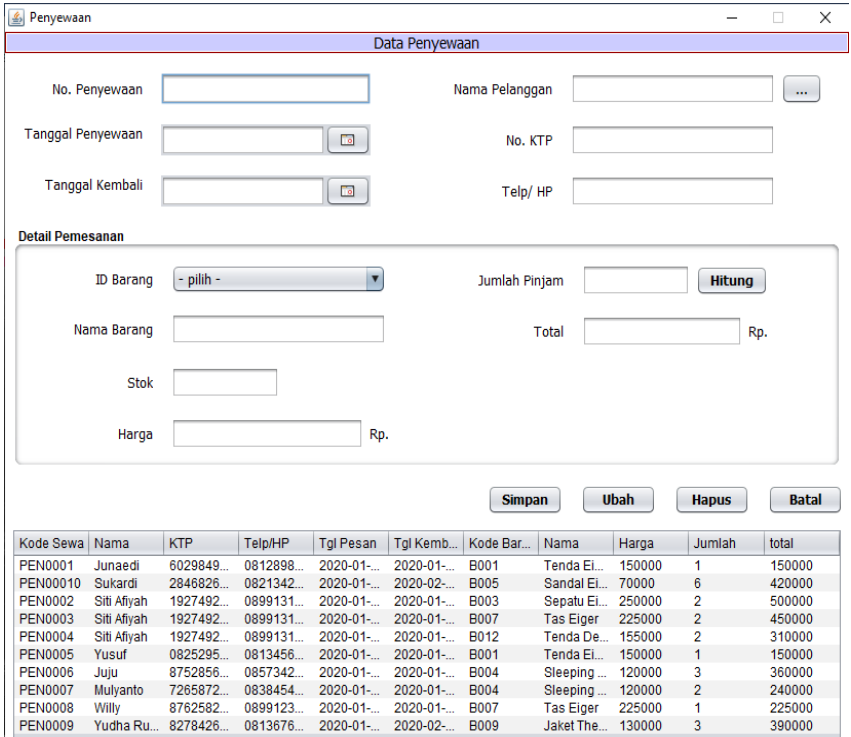

Gambar 6. Tampilan Layar Data Penyewaan

Layar di atas menampilkan tampilan form data penyewaan. Pada layar form data penyewaan untuk menginput data penyewaaan yang terdiri dari No Penyewaan, Tanggal Penyewaan, Tanggal Kembali, Nama Pelanggan, No KTP, Telp, ID Barang, Nama Barang, Jumlah Pinjam, dan Total Harga. 


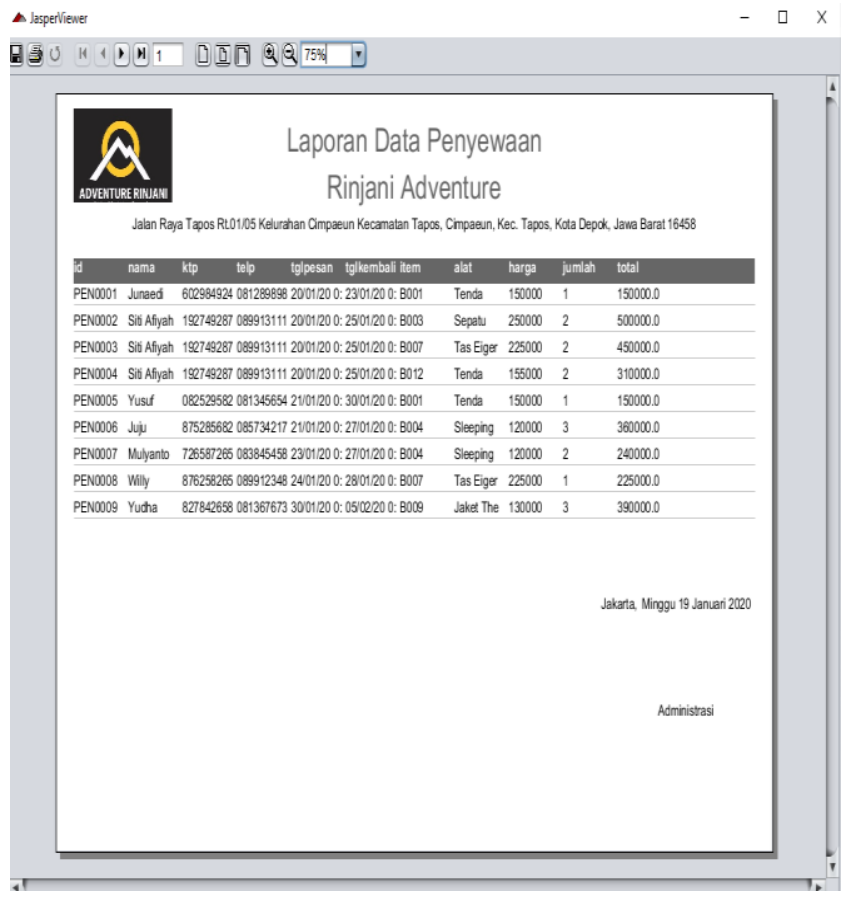

Gambar 7. Tampilan Laporan Data Penyewaan

Layar di atas menampilkan tampilan form laporan data penyewaan. Pada layar form laporan data penyewaan untuk mengecek laporan data penyewaan yang sudah terinput yang terdiri dari No Penyewaan, Tanggal Penyewaan, Tanggal Kembali, Nama Pelanggan, No KTP, Telp, ID Barang, Nama Barang, Jumlah Pinjam, dan Total Harga.

\section{SIMPULAN}

Hasil perancangan aplikasi sistem informasi penyewaan alat outdoor pada outlet Rinjani Adventure yang diusulkan menghasilkan sebuah rancangan aplikasi berbasis java yang menggunakan DBMS (Database Manajemen System) sebagai media penyimpanan data, hasil implementasi aplikasi sistem informasi penyewaan dapat mengoptimalkan aktivitas yang diusulkan pada outlet Rinjani Adventure dapat mengoptimalkan aktivitas pendataan daftar barang, persediaan stok barang, maupun proses penyewaan alat outdoor sehingga permasalahan yang dihadapi pada aktivitas-aktivitas tersebut dapat teratasi dengan baik, hasil pengujian aplikasi sistem informasi penyewaan alat outdoor pada outlet Rinjani Adventure sudah memenuhi fungsionalitas dari rancangan sistem yang diusulkan.

\section{DAFTAR PUSTAKA}

Jogiyanto. (2010). Analisis \& Desain Sistem. Yogyakarta: Andi Offset.

Pahlevi, D. S. M. (2013). Tujuh Langkah Praktis Pembangunan Basis Data. Jakarta: Elex Media Komputindo.

Shalahuddin, M. dan R. A. S. (2013). Rekayasa Perangkat Lunak Terstruktur Dan Berorientasi Objek. Bandung: Informatika Bandung.

Subekti. (2014). Aneka Perjanjian. Bandung: Citra aditya Bakti.

Tata Sutabri. (2012). Analisis Sistem Informasi. Yogyakarta: Andi Offset. 